\title{
Design of a Super Compact UWB Filter Based on Hybrid Technique with a Notch Band Using Open Circuited Stubs
} Hamza El Omari El Bakali ${ }^{1}$, Hanae Elftouh ${ }^{1}$, Abdelkrim Farkhsi ${ }^{1}$, Alia Zakriti ${ }^{2}$, and Mohssine El Ouahabi ${ }^{2}$

${ }^{1}$ Faculty of Sciences, Abdelmalek Essaadi University, Tetuan, Morocco.

${ }^{2}$ National School of Applied Sciences, Abdelmalek Essaadi University, Tetuan,

Corresponding author: e-mail: h.elomari@uae.ac.ma

\begin{abstract}
This paper presents a new design of a super compact ultra wideband (UWB) band-pass filter (BPF) with rejection of X-band satellite applications. For covering the UWB bandpass, the proposed filter is realized using hybrid technique which is achieved by using a microstrip-coplanar waveguide-microstrip transition. The basic structure consists of a modified microstrip in the top layer and CPW in the bottom layer. Later, open-circuited stubs are embedded in the top to implement in-band transmission zeros (TZ) so as to circumvent interference. The simulated results show that the UWB bandpass filter has a high adaptation $\left(\mathrm{S}_{11}\right.$ $\leq-18 \mathrm{~dB}$ ) and insertion loss better than $0.4 \mathrm{~dB}$ at the passband. The impedance bandwidths are about $114 \%$ (3-11 GHz) with upper stopband extends to more than $14 \mathrm{GHz}$ with a depth of greater than $38 \mathrm{~dB}$. In addition, the UWB BPF shows a flat group delay performance with a variation of about 0.15 ns over the entire bandwidth. A prototype of the filter is fabricated and tested. Good agreement is achieved between measurement and simulation. The proposed UWB BPF is compact in size with overall dimensions of 14 by $9.2 \mathrm{~mm}^{2}$. Consequently, the obtained results prove that the presented filter is suitable for UWB wireless devices.
\end{abstract}

INDEX TERMS bandpass, coplanar, filter, microstrip, hybrid technique, UWB, SRR

\section{INTRODUCTION}

$\mathbf{U}^{1}$ LTRA-Wideband (UWB) radio technology has gained much attention in recent years for high-speed wireless connectivity applications. It has many potential applications to be researched, such as imaging system, communications and measurements, vehicular radar, surveillance, medical systems, and satellite communications [1]. These applications benefit from the unique features of low-power spectral density and consumption associated with UWB systems. To transmit or receive a high-quality signal, an UWB bandpass filter (UWB BPF) must have a wide bandwidth of about $20 \%$ or greater, and a high selectivity [1].

There are many techniques presented to design UWB BPF like defected ground structure (DGS) [2,3], multiple-mode resonator (MMR) [4], modified split ring resonator (MSRR) [5], multilayer coupled structure [6] and surface-to-surface broadside coupled structures that have exhaustively been used in the design of UWB-BPFs [7-9]. The microstrip-to CPW-based UWB filters, compared with the rest, have minimum insertion loss response in the passband due to the tight broadside coupling of the structure [10]; these techniques have been widely used to achieve UWB characteristics.

However, UWB communication systems could be easily interfered by one or more of the nearby communication systems such as WiMAX communication system operating at
(3.3-3.7) GHz, WLAN system operating at the lower part or the upper part of the (5.15-5.85) $\mathrm{GHz}$ band and X-band downlink communication frequency operating at (7.10-7.76) GHz. So compact UWB BPFs with notched band are emergently required to reject these interfering signals.

Hence, adding bandstop filters (BSF) to the design is among solutions to tackle the problem of interferences, previously mentioned, but appending the BSF to the existing bandpass filter of the UWB system causes an increase in circuit size. So, researchers overcame this drawback by integrating the BSF within the BPF, thereby keeping the circuit size to minimum. This necessity led to an exhaustive amount of research into the design and development of notched band UWB filters [1116]. It's to highlight that several works have studied notches using multiple methods, for example, notch implementation using open stubs is proposed in [11-13]. The stepped impedance resonator is utilized in [12], to generate passband notch. Defected microstrip structure (DMS) in [14] and defected ground structure (DGS) in [15]. Furthermore, parallel defected microstrip structures (PDMSs) are used to create notches in [16]. However, the design of a compact notched band UWB filter with better performance remains a challenge at large.

To overcome this challenge, we propose in this paper an UWB-BPF with notched band which is generated at $7 \mathrm{GHz}$, $\mathrm{X}$-band downlink satellite communication, using the 
microstrip open circuited stub with suppression greater than $18 \mathrm{~dB}$. The proposed UWB filter is constructed on a single dielectric RT/Duroid 6010 substrate of permittivity equal to 10.8 and height about $0.635 \mathrm{~mm}$. The design of proposed structure is based on hybrid technique. Initially, the basic UWB is developed using microstrip/coplanar waveguide (CPW) technology to fabricate miniaturized structures with several advantages for millimeter-wave applications such as small loss, less radiation at discontinuities, low cost and ease of fabrication with good performance. Secondly, open circuited stubs are implemented in order to affect the resonance frequency and then to generate notches which act like the stopband filters.

\section{GEOMETRY OF UWB FILTER}

The proposed UWB BPF is fabricated on a RT/Duroid 6010 dielectric substrate, with a dielectric constant of 10.2, loss tangent of 0.0023 for a broad bandwidth and a thickness of $0.635 \mathrm{~mm}$. Figure 1 illustrates the design of the UWB BPF. Indeed, we can see that the microstrip technique is used on the top layer Figure1(a) and a CPW is used on the ground plane Figure 1(b). As shown in Figure 1(a), we choose the U-shaped resonators technique which is loading a microstrip line to cover a frequency band from 3 to $11 \mathrm{GHz}$. This technique is more detailed in the next section. In addition, a rectangular part is cut from the bottom layer to improve impedance matching.

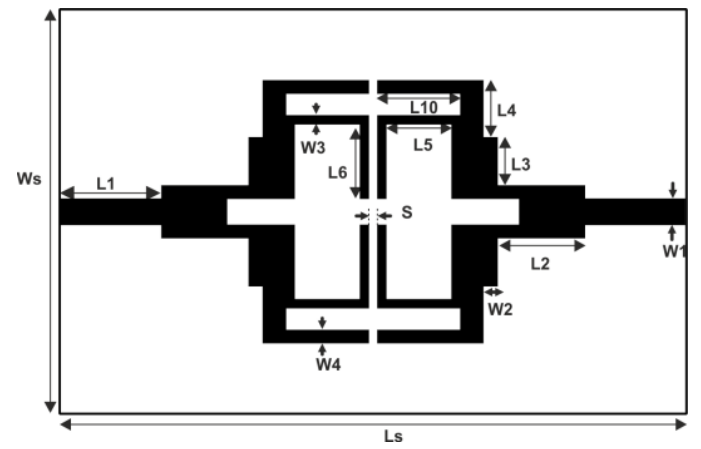

(a)

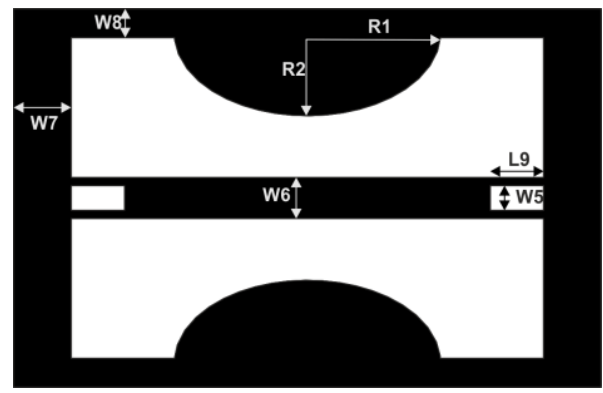

(b)

FIGURE 1. Geometry of the proposed UWB BPF: (a) top view, (b) bottom view.
The structural parameters for the optimal UWB filter circuit are summarized in Table1.

TABLE I. Dimensions of the proposed UWB BPF

\begin{tabular}{cccccccc}
\hline \hline Parameters & $\mathrm{Ls}$ & $\mathrm{Ws}$ & $\mathrm{L}_{1}$ & $\mathrm{~L}_{2}$ & $\mathrm{~L}_{3}$ & $\mathrm{~L}_{4}$ & $\mathrm{~L}_{5}$ \\
\hline Values $(\mathrm{mm})$ & 14 & 9.2 & 2 & 2 & 1.1 & 1.3 & 1.5 \\
\hline Parameters & $\mathrm{L}_{6}$ & $\mathrm{~W}_{2}$ & $\mathrm{~W}_{1}$ & $\mathrm{R}_{1}$ & $\mathrm{~L}_{10}$ & $\mathrm{~W}_{3}$ & $\mathrm{~W}_{4}$ \\
\hline Values $(\mathrm{mm})$ & 1.9 & 0.32 & 0.6 & 3.2 & 1.9 & 0.2 & 0.3 \\
\hline Parameters & $\mathrm{S}$ & $\mathrm{L}_{9}$ & $\mathrm{~W}_{5}$ & $\mathrm{~W}_{6}$ & $\mathrm{~W}_{7}$ & $\mathrm{~W}_{8}$ & $\mathrm{R}_{2}$ \\
\hline Values $(\mathrm{mm})$ & 0.2 & 1.3 & 0.6 & 1 & 1.4 & 0.7 & 2 \\
\hline \hline
\end{tabular}

It should be noted that the length $\mathrm{L}_{2}+\mathrm{L}_{3}+\mathrm{L}_{4}+\mathrm{L}_{10}$ is initially set to a half wavelength, and after that, the optimization is done for better results. However, concerning the parameters $\mathrm{W}_{2}$, $\mathrm{W}_{7}, \mathrm{R}_{1}$ and $\mathrm{R}_{2}$, they are based on optimization process while keeping the transition microstrip-coplanar-microstirp of the studied structure.

\section{DESIGN EVOLUTION PROCESS OF THE COMPACT UWB FILTER}

In this section we will detail the important steps to improve the studied filter starting with the role of each U-shaped resonators and slots. Indeed, as we will see in what follows, the purpose of adding U-shaped resonators is to broaden the bandwidth; on the other hand, the advantage of adding slots on bottom is to improve matching impedance and then studied filter's performances. Finally, we will show the advantage of semiellipse conductor in CPW at the bottom layer.

\section{A. EVOLUTION OF FILTER DESIGN WITH SEMI- \\ ELLIPSE}

The design evolution of our compact UWB filter is depicted in Figures 2, 3, 4 and 5, with corresponding results of simulated S-parameter of each step. Due to the symmetry of the structure, only the $\mathrm{S}$-parameters $\left(\mathrm{S}_{11}\right.$ and $\left.\mathrm{S}_{21}\right)$ are presented.
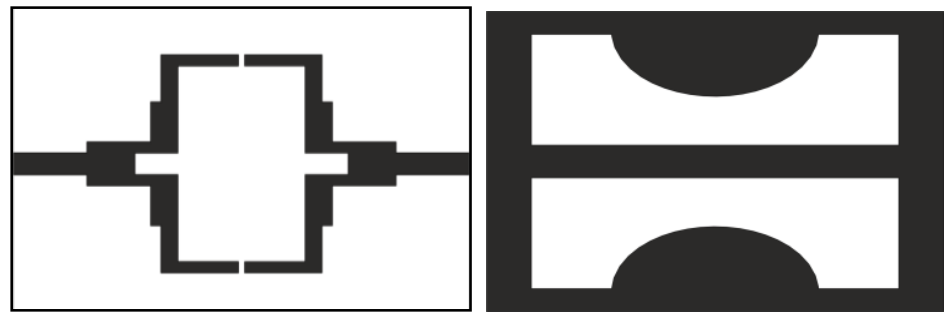

(a)

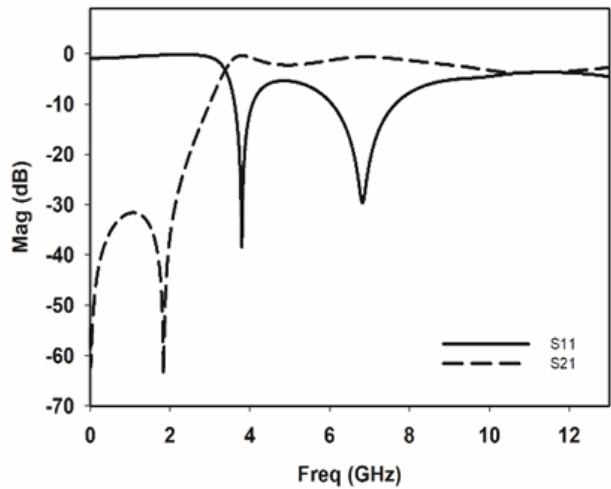

(b) 
FIGURE 2. Geometry and simulation of the first filter design (a) Top and bottom view, (b) S-parameters.

From Figure 2 (a), we can see that on the top side of the substrate, the microstrip is integrated without U-shaped resonators inside the structure and $\mathrm{CPW}$ is used on the bottom. From Figure 2(b), it can be seen that $S_{11}$ is worse than $10 \mathrm{~dB}$ in the pass band with poor $S_{21}$ response in upper stop band. The result of this step shows that the proposed filter does not cover the UWB band, and then it is not adapted to the UWB band.

In order to improve the bandwidth of the proposed UWB BPF, we change the structure by adding four U-shaped resonators as shown in Figure 3(a). The length of the U-shaped resonators is $\left(\mathrm{L}_{5}+2 \mathrm{~L}_{6}\right)$ and it is about one-half wavelength of the central frequency $(6.85 \mathrm{GHz})$ of the microstrip filter. As can be seen from Figure 3(b), the bandwidth has been improved as it has become extended from $(3.5-10 \mathrm{GHz})$ to (3$12 \mathrm{GHz}$ ). In addition, the appearance of three poles is observed in the passband.
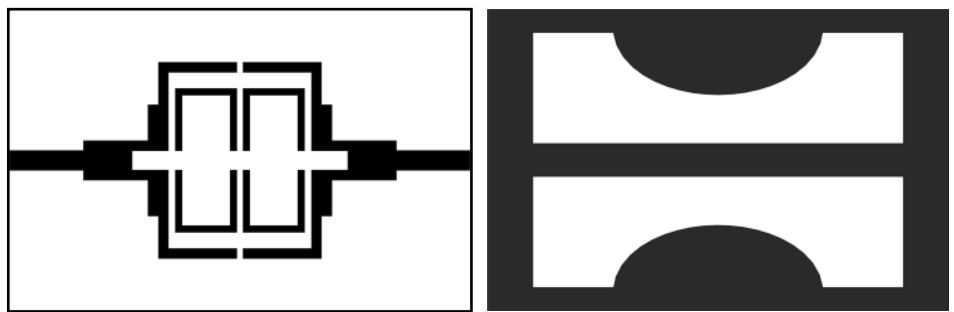

(a)

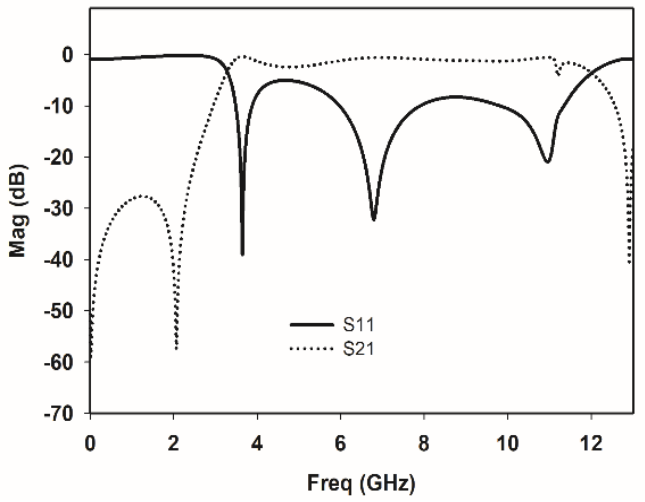

(b)

FIGURE 3. Geometry and simulation of the second filter design (a) Top and bottom view, (b) S-parameters.

Next step we added a short circuit between line microstrip and U-shaped resonators, as seen in Figure 4 (a). And from Figure 4 (b) we can see that the bandwidth is adjusted to cover the band recommended by FCC and the impedance matching has been improved in the bandwidth especially between 6 and 9 $\mathrm{GHz}$, and it became better than $12 \mathrm{~dB}$. Also there has been an improvement in the parameter S21 (better than $15 \mathrm{~dB}$ ), in the rejected band.
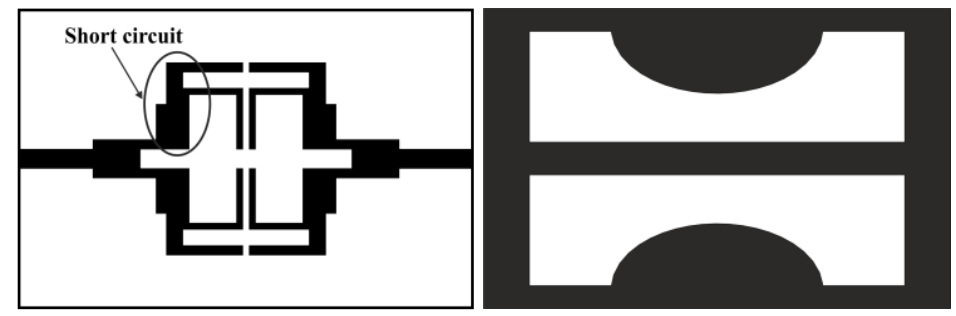

(a)

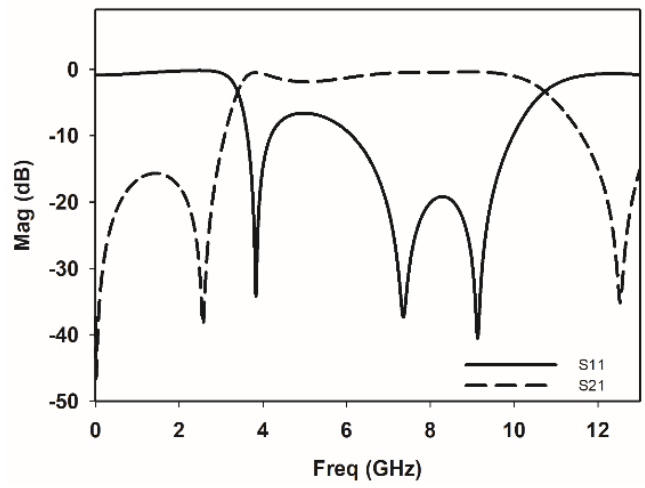

(b)

FIGURE 4. Geometry and simulation of the third filter design (a) Top and bottom view, (b) S-parameters.

In order to further improve matching impedance, we etched two rectangular slots on bottom as shown in Figure 5(a) where length $\left(\mathrm{L}_{9}\right)$ and width $\left(\mathrm{W}_{5}\right)$ are respectively $1.3 \mathrm{~mm}$ and 0.6 $\mathrm{mm}$ which are found based on parametric optimization (Figure 6 (b), (c)). So, we can conclude that after the addition of these slots, we have a strong improvement in terms of adaptation between the two frequencies 4 and $8 \mathrm{GHz}$ as seen in Figure 5(b). Also, the proposed UWB filter has an insertion loss better than $0.5 \mathrm{~dB}$ from 3 to $11 \mathrm{GHz}$ and the return loss is less than $15 \mathrm{~dB}$ over most part of the passband.
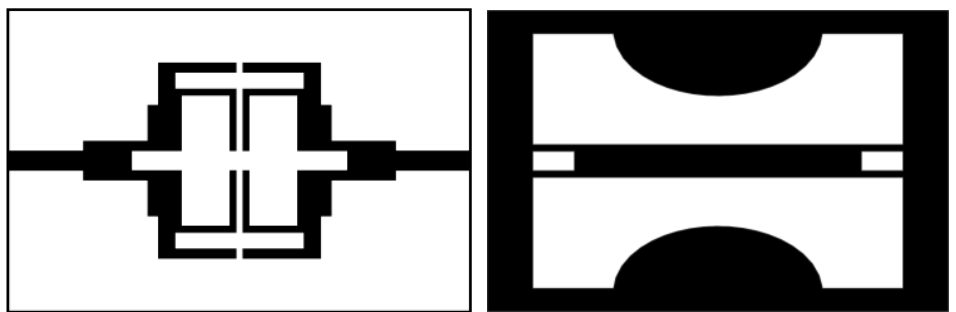

(a) 


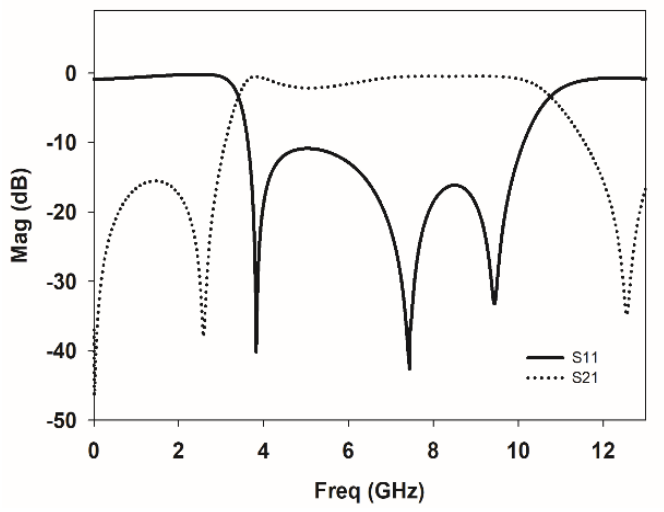

(b)

FIGURE 5. Geometry and simulation of the fourth filter design (a) Top and bottom view, (b) S-parameters.

Finally, we choose the last design of the proposed UWB $\mathrm{BPF}$, which gives the best results.

\section{B. PARAMETRIC STUDY}

In this section, we present a parametric study of the proposed filter by studying the effects of the principal parameters of the structure, with keeping the other dimensions constant. The parameter S11 of the proposed filter is given with varying length of the U-shaped resonators (L6), width (W5) and length (L9) of the slot rectangular and width of CPW (W6) line respectively.

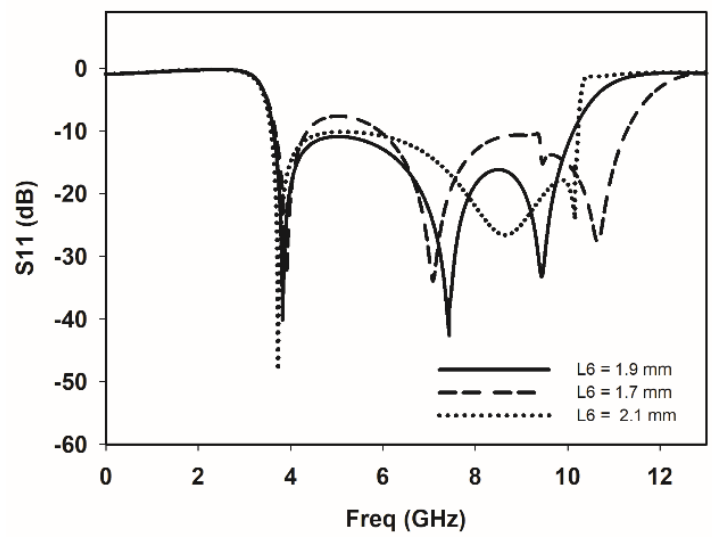

(a)

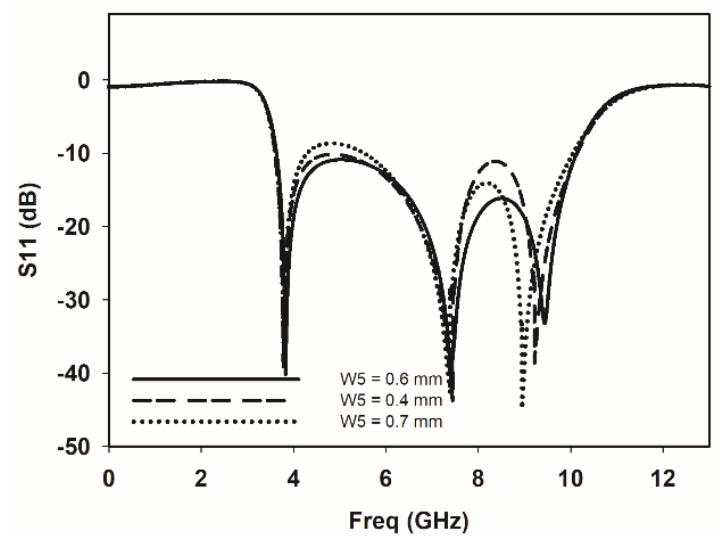

(b)

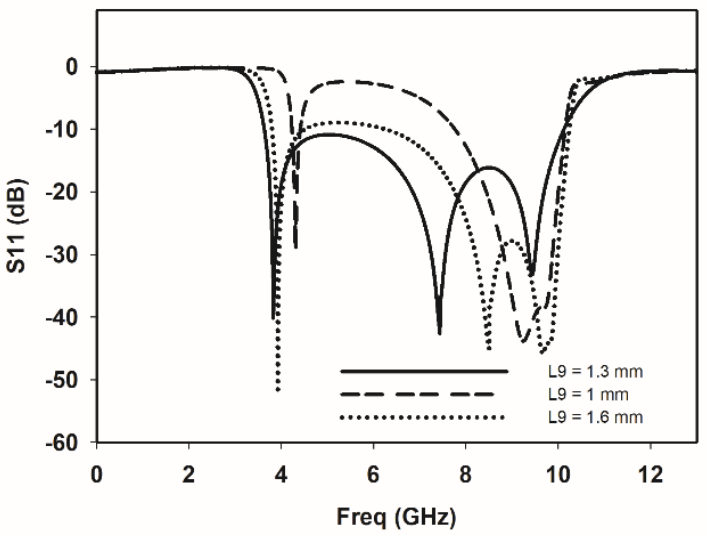

(c)

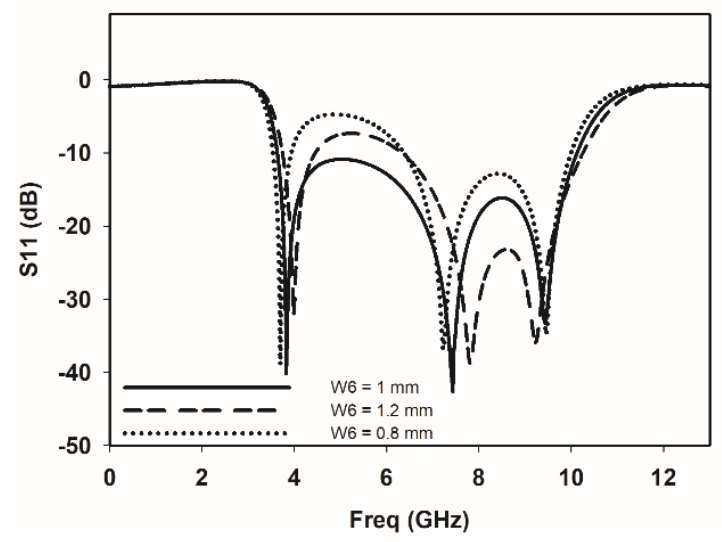

(d)

FIGURE 6. The effect of: (a) Length of U-shaped resonators, (b) Width of rectangular slot, (c) Length of rectangular slot (d) Width of CPW line.

As shown in Figure 6(a) to adjust the bandwidth frequency, the L6 value has been changed from 1.5 to $2.1 \mathrm{~mm}$. L6 is found to be $1.9 \mathrm{~mm}$ to cover the UWB frequency band $(3-11 \mathrm{GHz})$ with good adaptation. To improve impedance matching, we 
changed W5 value from 0.4 to $07 \mathrm{~mm}$. As can be seen clearly in Figure 6(b), the adjusted value for W5 is found to be 0.6 $\mathrm{mm}$ for the best adaptation. From Figure 6(c), we notice an improvement at the impedance matching level and bandwidth when $\mathrm{L} 9=1.3 \mathrm{~mm}$.

Finally, as depicted in Figure 6(d), we can observe that by varying the W6 value from 1.2 to $0.8 \mathrm{~mm}$, a good impedance matching is obtained across the whole band, for W6 equal to $1 \mathrm{~mm}$.

\section{CHOICE OF SEMI-ELLIPSE CONDUCTOR IN CPW}

In this section we made a comparison between the ellipse structure and the rectangular structure which is the most widespread in the literature. The following study shows the difference between the two structures always with the aim of improving the performance of our studied filter.

In Figure 7 (a) we show the two structures and in Figure 7

(b) we compare the simulation results of S11 and S21 with semi-ellipse conductor and rectangular conductor in $\mathrm{CPW}$ at bottom layer.
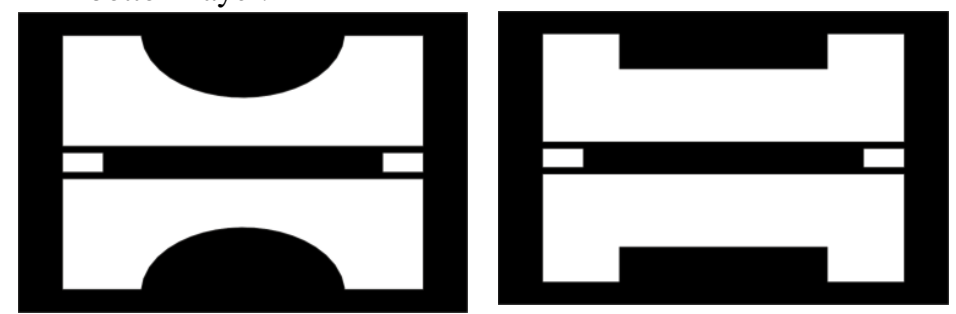

(a)

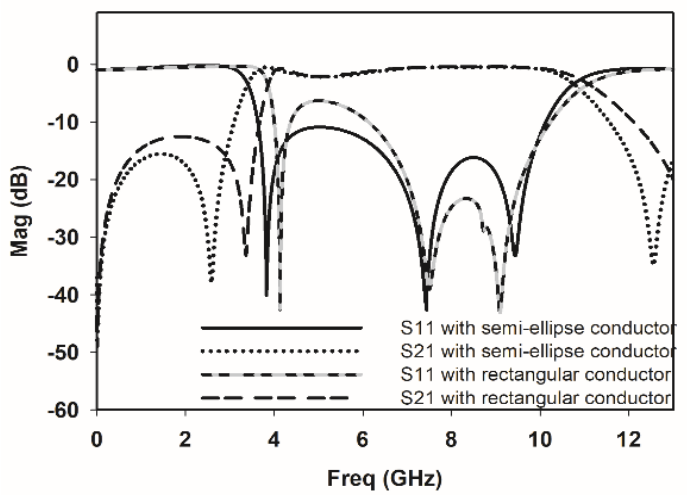

(b)

FIGURE 7. (a) Bottom layer with rectangular and semi-ellipse conductor, (b) Compared S-parameters.

From what we saw in the above, the importance of semiellipse is widening the bandwidth, especially the part of the low frequencies. We can conclude that with the use of semiellipse in the bottom of the studied filter, the bandwidth has been extended from (4-11) GHz to (3-11) GHz and also, we notice that there is an improvement in the level of insertion loss

\section{NOTCHED BAND IMPLEMENTATION}

As mentioned above, the problem of interference between UWB devices and systems is an important issue in developing a UWB radio module or system. In order to circumvent these interferences, our UWB filter is modified so as to work efficiently in indoor environment. To the proposed UWB filter structure, we implement a notched band which can be adjusted easily. The notched band is introduced by open circuited stubs on the both sides of the Microstrip line as shown in Figure 8(a).

The designed central frequency of the notch-band can be achieved by adjusting the length of stubs open circuited which is about half wavelength at the desired frequency. That is to say, each open circuited stub is a quarter-wavelength resonator. The resonant frequency can be expressed as:

$$
\begin{gathered}
f_{\text {notch }}=\frac{c}{4(L 7+L 8) \sqrt{\varepsilon_{e f f}}} \\
\varepsilon_{\text {eff }}=\frac{\varepsilon_{r}+1}{2}
\end{gathered}
$$

where $\varepsilon_{e f f}$ is the effective dielectric constant of microstrip line, $C$ is the speed of light and $\left(\mathrm{L}_{7}+\mathrm{L}_{8}\right)$ is length of the stub.

The optimal values of $L_{7}$ and $L_{8}$ were found to be respectively, $1.67 \mathrm{~mm}$ and $2 \mathrm{~mm}$

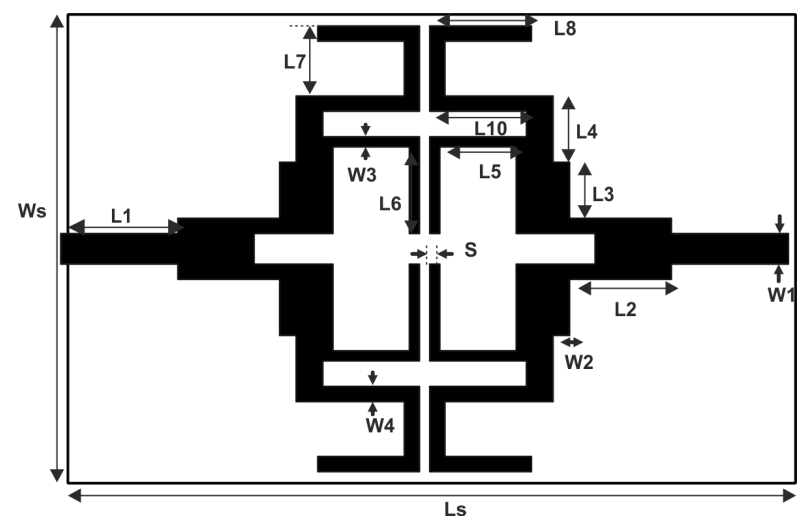

(a)

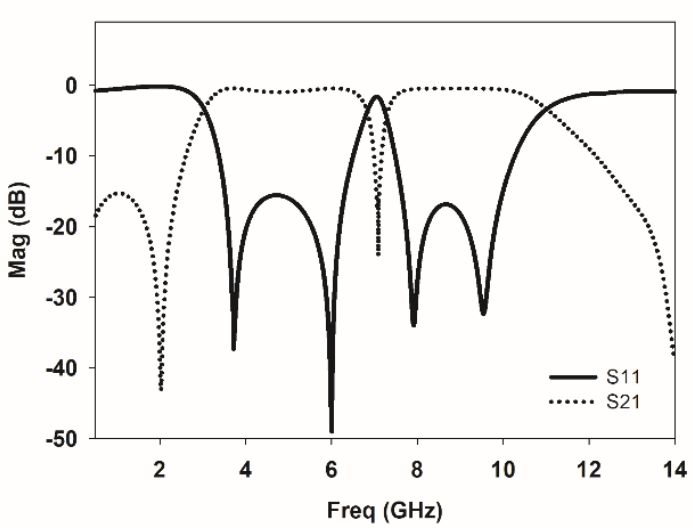

(b)

FIGURE 8. Geometry and simulation of the proposed UWB BPF with notched band: (a) Top and bottom view, (b) S-parameters. 
From Figure 8(b), we observe that the upper stopband extends up to $14 \mathrm{GHz}$ with attenuation greater than $38 \mathrm{~dB}$. Computed return loss results were better than $18 \mathrm{~dB}$ over the passband. Moreover, we can notice that the impedance matching is improved by introducing the open circuited stubs. The maximum insertion loss observed in the passband before the notch and after the notch is $0.4 \mathrm{~dB}$. For the rejected band, the results show that a $24 \mathrm{~dB}$ insertion loss at the centre notch frequency at $7 \mathrm{GHz}$ (X-band downlink satellite communication frequency) is observed.

Finally, current distributions are used to confirm the resonant conditions of this UWB filter. Figure 9 depicts the current response at notch frequency of $7 \mathrm{GHz}$. As shown in this Figure, at $7 \mathrm{GHz}$ notched frequency, the current is mainly focused over open circuited stubs and it is very low in the rest of the structure. However, there is no current near the output port, which implies that there is no signal propagation in the filter and the circuit is in the stopband state. So, it has been proved that the open circuited stubs generate transmission zeros (TZ) at $7 \mathrm{GHz}$ in order to eliminate interference of $\mathrm{X}$ band downlink satellite communication frequency.

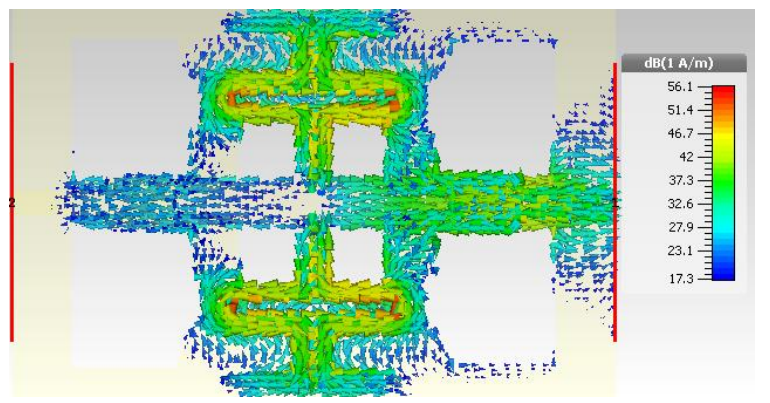

FIGURE 9. Surface current density at $7 \mathrm{GHz}$.

As seen in Figure 10, another parameter is studied to verify that all signals are delayed when they pass through our proposed filter. For an efficient filter, the group delay would be constant to avoid distortions. It can be expressed as:

$$
\begin{gathered}
\tau_{d}=\frac{d \varphi_{21}(\omega)}{-d \omega} \\
\varphi_{21}(\omega)=\arg S_{21}(\omega)
\end{gathered}
$$

Where $\tau_{d}$ is the group delay and $\varphi_{21}$ is the phase response.

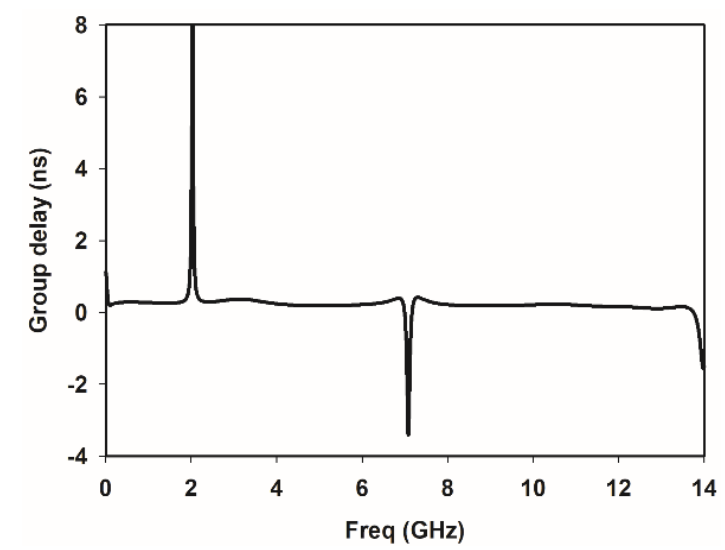

FIGURE 10. simulated group delay.

From the Figure 10, we can conclude that the group delay is about $0.15 \mathrm{~ns}$ over $3-11 \mathrm{GHz}$ band, except at the $7 \mathrm{GHz}$ frequency which is checked for proper functioning.

\section{EXPERIMENTAL RESULTS AND DISCUSSION}

After doing the EM simulation using Computer Simulation Technology (CST) Microwave Studio Software, the proposed filter is fabricated using LPKF protoMat and the prototype was tested using a Rohde and Schwarz ZVB 20 Vector Network Analyzer. Figure 11 shows the fabricated UWB bandpass filter photographs.

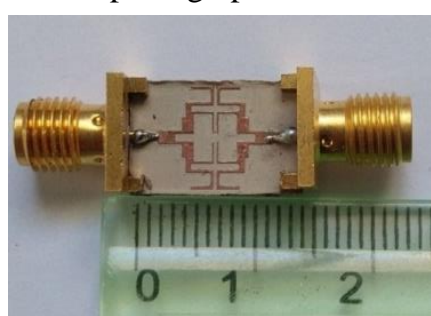

(a)

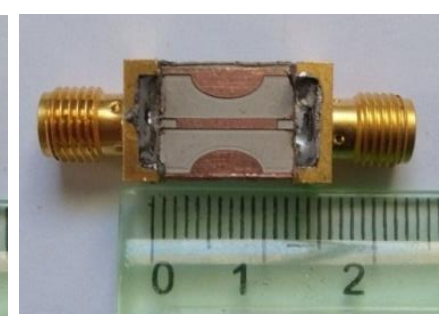

(b)
FIGURE 11. Photograph of the fabricated prototype: (a) Top view, (b) bottom view.

It can be seen, from Figure 12(a), that there is a good agreement between the simulated and measured results

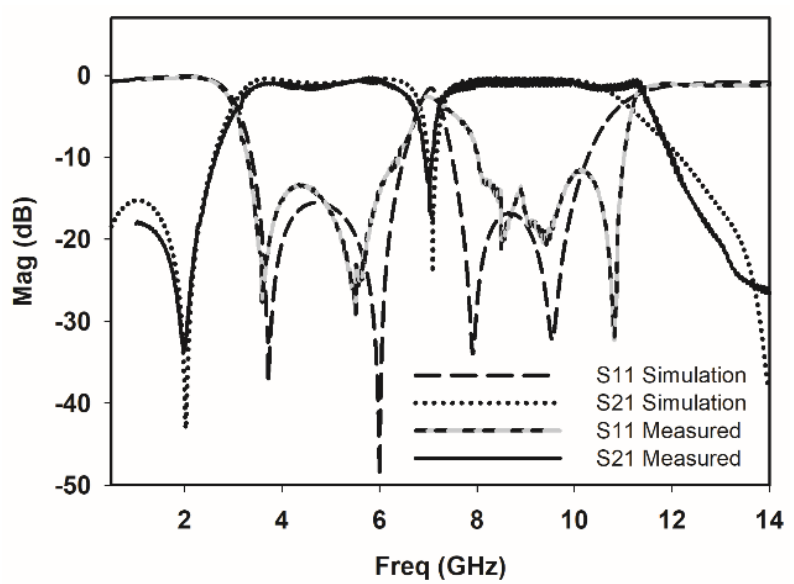

FIGURE 12. Simulated and measured S-parameters of the proposed filter. 
There are several main factors of the total loss of the measured frequency responses mainly, manufacturing tolerances, conductor loss, the tolerance in the dielectric permittivity and also connectors mismatch.

We observe from Figure 11 that the measured insertion loss is less than $0.4 \mathrm{~dB}$, the return loss is above $18 \mathrm{~dB}$ and the attenuation is more than $24 \mathrm{~dB}$ at the frequency near the notched band $7 \mathrm{GHz}$. The upper stopband is up to $14 \mathrm{GHz}$ with rejection greater than $38 \mathrm{~dB}$

Comparisons with other reported UWB BPF's with notched band are listed in Table 2, which demonstrates that the proposed filter has good characteristics and very small size.

TABLE 2. The presented UWB BPF and recently reported filters comparison

\begin{tabular}{ccccc}
\hline \hline Ref & $\begin{array}{c}\text { Pass band } \\
(\mathrm{GHz})\end{array}$ & $\begin{array}{c}\text { Insertion } \\
\text { loss } \\
(\mathrm{dB})\end{array}$ & $\begin{array}{c}\text { Notch } \\
\text { frequency } \\
(\mathrm{GHz})\end{array}$ & $\begin{array}{c}\text { Circuit size } \\
\mathrm{mm}^{2}\end{array}$ \\
\hline$[17]$ & $3.1-10.6$ & 0.6 & $8.1 / 18$ & $\begin{array}{c}21.84 \times \\
\text { Attenuation(dB) }\end{array}$ \\
\hline$[18]$ & $3.7-11.6$ & 0.45 & $7 / 20$ & $17.6 \times 9.6$ \\
\hline$[19]$ & $3-12.2$ & NOT & $6.7 / 20$ & $24.78 \times 12.4$ \\
\hline$[20]$ & $3-10$ & $>2.5$ & $5.5 / 22$ & $27.04 \times 10$ \\
\hline$[21]$ & $2.35-$ & 0.7 & $8.2 / 42$ & $13.22 \times 10.71$ \\
\hline$[22]$ & $2.3-11.7$ & NOT & $5.5 / 32$ & $38 \times 32$ \\
\hline$[23]$ & $3.4-10$ & 2 & $5.2 / 22.7$ & $32.3 \times 13$ \\
\hline$[24]$ & $2-9$ & 2 & $5.8 / 30$ & $26.7 \times 15$ \\
\hline$[25]$ & $2.9-12.2$ & $<0.5$ & $5.8 / 30$ & $30 \times 15$ \\
\hline This & $3-11$ & $<0.4$ & $7 / 24$ & $14 \times 9.2$ \\
work & & & & \\
\hline \hline
\end{tabular}

\section{CONCLUSION}

This paper proposes a new super compact UWB BPF with notch. The basic UWB filter is based on CPW in the ground coupled to microstrip lines in the top layer using U-shaped resonator, rectangular slot and semi-ellipse. The passband encompasses the requisite UWB $(3-11 \mathrm{GHz})$ and the stopband is wide and deep till $15 \mathrm{GHz}$ with attenuation greater than $38 \mathrm{~dB}$. Open circuited stubs coupled to the microstrip lines are integrated into the UWB filter to generate notch band at $7 \mathrm{GHz}$. Also, the group delay variation is about $0.15 \mathrm{~ns}$ in the passband. Owing to its compact size and satisfactory passband and stopband performances, these results prove that the proposed filter is a good candidate for modern small wireless communication systems and UWB systems with high- performances.

\section{ACKNOWLEDGMENT}

This work was achieved by the efforts of all the authors of this paper. We would like to thank, then, Professor Naima Amar Touhami from the laboratory of Information Systems and Telecommunications, Faculty of Sciences, Abdelmalek Essaadi University, Tetuan, Morocco for her fruitful guidance and her professional support with regards to the measure of the proposed filter.

\section{REFERENCES}

[1] H. E. O. El Bakali, A. Zakriti, A. Farkhsi, and A. Marroun, "Miniaturized UWB bandpass filter using hybrid techniques," 2019 International Conference on Wireless Technologies, Embedded and Intelligent Systems, WITS 2019, IEEE, no. September, pp. 1-4, 2019.

[2] J. Lu, J. Wang, and H. Gu, "Design of compact balanced ultra-wideband bandpass filter with half mode dumbbell DGS," Electronics Letters, vol. 52, no. 9, pp. 731-732, 2016.

[3] Y. Saini and M. Kumar, "Design and Analysis of Compact UWB Bandpass Filter with Wide Passband Using Defected Ground Structure," American Journal of Engineering Research (AJER), no. 08, pp. 267-272, 2014

[4] L. Zhu, S. Sun, and W. Menzel, "Ultra-Wideband (UWB) bandpass filters using multiple-mode resonator," IEEE Microwave and Wireless Components Letters, vol. 15, no. 11, pp. 796-798, 2005.

[5] A. Kamma, G. S. Ready, P. Suggisetti, and J. Mukherjee, "A novel and compact ultra-wide band (UWB) filter using modified split ring resonator (MSRR)," IEEE MTT-S International Microwave and RF Conference 2014, IMaRC 2014 - Collocated with Intemational Symposium on Microwaves, ISM 2014, IEEE, vol. 8, pp. 69-71, 2015.

[6] D. Packiaraj, K. J. Vinoy, and A. T. Kalghatgi, “Analysis and design of a compact multilayer ultra wide band filter," Progress In Electromagnetics Research C, vol. 7 , pp. 111-123, 2009.

[7] H. E. O. El Bakali, A. Zakriti, A. Farkhsi, A. Mchbal, and M. El Ouahabi, "Design of a compact UWB BPF using a hybrid structure and a staircase-shaped DGS,' International Journal of Microwave and Optical Technology, vol. 14, no. 5, pp. 306-313, 2019.

[8] J. W. Baik, T. H. Lee, and Y. S. Kim, "Novel broadband microstrip-to-CPW transition with easy transmission band control," IEICE Electronics Express, vol. 5, no. 2, pp. 48-52, 2008

[9] A. N. Ghazali, M. Sazid, and B. Virdee, "A compact UWB-BPF based on microstrip-to-CPW transition with multiple transmission zeros," Microwave and Optical Technology Letters, vol. 60, no. 8, pp. 1925-1928, 2018.

[10] 1A. N. Ghazali, J. Hussain, and S. Pal, "A hybrid surfaceto-surface transition-based UWB-BPF with multiple inband interference suppression," International Journal of Microwave and Wireless Technologies, vol. 11, no. 2, pp. 168-174, 2019.

[11] X. Liu, C. Zhong, H. Song, Y. Chen, and T. Luo, "A new compact microstrip UWB bandpass filter with triplenotched bands and good stopband performance," Progress in Electromagnetics Research Letters, vol. 72 , no. September 2017, pp. 29-37, 2018.

[12] J. Liu, J. Lu, Z. He, T. Luo, X. Ying, and J. Zhao, "Super compact microstrip UWB BPF with triple-notched bands," Progress in Electromagnetics Research Letters, vol. 73, no. November 2017, pp. 61-67, 2018.

[13] S. Pankaj, P. Manimala, G. Rowdra, and D. R. Poddar, "MINIATURIZED UWB BANDPASS FILTER WITH DUAL NOTCH BANDS AND WIDE UPPER STOPBAND," Progress In Electromagnetics Research Letters, Vol. 38, 161-170, 2013, vol. 38, no. March, pp. 161-170, 2013.

[14] . C. Gupta, M. Kumar, and R. S. Meena, "Design and Analysis of Triple Notched Band Uwb Band Pass Filter Using Defected Microstrip Structure (Dms), 
International Journal of Wireless Communications and Mobile Computing, vol. 5, no. 6, p. 32, 2017.

[15] J. Liu, W. Ding, J. Chen, and A. Zhang, "New ultrawideband filter with sharp notched band using defected ground structure," Progress in Electromagnetics Research Letters, vol. 83, no. April, pp. 99-105, 2019.

[16] F. Liu and M. Qun, "A new compact UWB bandpass filter with quad notched characteristics," Progress in Electromagnetics Research Letters, vol. 88, no. December 2019, pp. 83-88, 2020.

[17] G. Karimi, F. Khamin-hamedani, and hesam Siahkamari, "Compact UWB BPF using slotted resonator with an independently controllable notched band," International Journal of Microwave and Wireless Technologies, no. 1, pp. 1-7, 2014.

[18] S. Pirani, J. Nourinia, and C. Ghobadi, "Band-notched UWB BPF design using parasitic coupled line," IEEE Microwave and Wireless Components Letters, vol. 20, no. 8, pp. 444-446, 2010.

[19] T. Firmansyah, G. Wibisono, and E. T. Rahardjo, "Compact UWB Bandpass Filter based on Crossed Dumbbell-Stub with Notch Band using Defected Microstrip Structure,” 2019 16th International Conference on Quality in Research (QIR): International Symposium on Electrical and Computer Engineering,IEEE, pp. 1-5, 2019.

[20] A. Neogi, J. R. Panda, S. Sil, S. Chakraborty, A. Tarafdar, and W. Bengal, "A UWB Band-pass Filter with a WLAN Notch based on Multi-mode Resonator Structure for Application in Wireless Communication," 2019 Devices for Integrated Circuit (DevIC). IEEE, vol. 3, no. filter 1, pp. 23-24, 2019.

[21] K. Wang, S. W. Wong, and Q. X. Chu, "A compact UWB CPW bandpass filter with short-ended $\mathrm{H}$-shaped resonator and controllable notched band," IEICE Electronics Express, vol. 55, no. 7, pp. 1577-1581, 2017.

[22] R. S. Sangam and R. S. Kshetrimayum, "Notched UWB filter using exponential tapered impedance line stub loaded microstrip resonator," The Journal of Engineering, vol. 2018, no. 9, pp. 768-772, 2018.

[23] M. Weng, C. Hsu, S. Lan, and R. Yang, "An UltraWideband Bandpass Filter with a Notch Band and Wide Upper Bandstop Performances," Electronics, 2019.

[24] X. Ji, W. Ji, L. Feng, Y.-Y. Tong, and Z.-Y. Zhang, "Design of a Novel Multi-Layer Wideband Bandpass Filter," Progress In Electromagnetics Research Letters, vol. 82, no. December 2018, pp. 9-16, 2019.

[25] H. El, O. El, H. Elftouh, A. Farkhsi, A. Zakriti, and H. El Omari, " A Compact UWB Bandpass Filter with WLAN Band Rejection Using Hybrid Technique," Procedia Manufacturing, vol. 46, pp. 922-926, 2020. 